1

2

3

4

5

6

7

8

9

10

\title{
In silico studies of the biomolecular interactions between natural products and SARS-CoV-2 main protease
}

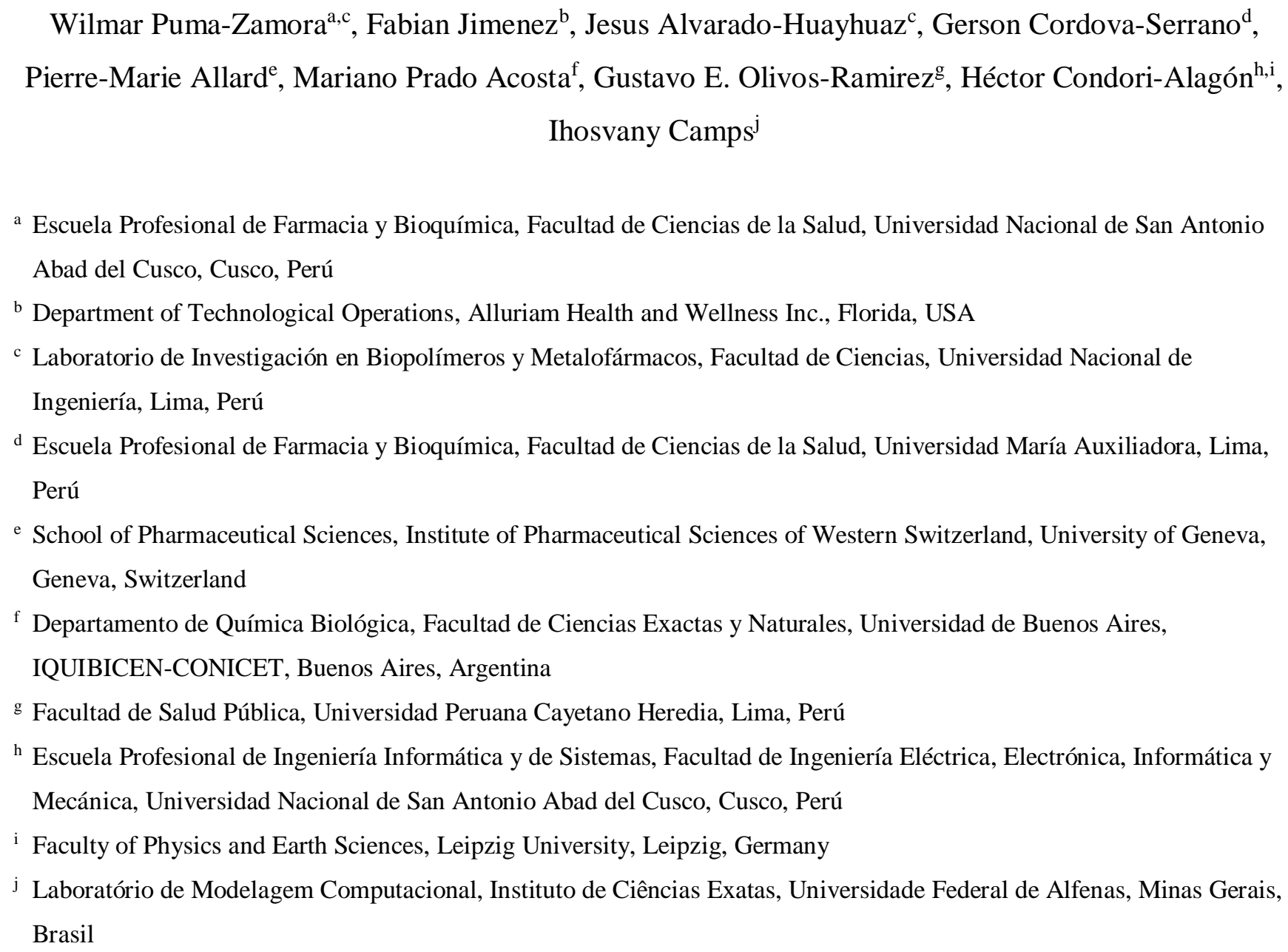

${ }^{d}$ Escuela Profesional de Farmacia y Bioquímica, Facultad de Ciencias de la Salud, Universidad María Auxiliadora, Lima, Perú

e School of Pharmaceutical Sciences, Institute of Pharmaceutical Sciences of Western Switzerland, University of Geneva, Geneva, Switzerland

f Departamento de Química Biológica, Facultad de Ciencias Exactas y Naturales, Universidad de Buenos Aires, IQUIBICEN-CONICET, Buenos Aires, Argentina

g Facultad de Salud Pública, Universidad Peruana Cayetano Heredia, Lima, Perú

${ }^{\text {h }}$ Escuela Profesional de Ingeniería Informática y de Sistemas, Facultad de Ingeniería Eléctrica, Electrónica, Informática y Mecánica, Universidad Nacional de San Antonio Abad del Cusco, Cusco, Perú

${ }^{\text {i }}$ Faculty of Physics and Earth Sciences, Leipzig University, Leipzig, Germany

j Laboratório de Modelagem Computacional, Instituto de Ciências Exatas, Universidade Federal de Alfenas, Minas Gerais, Brasil

\section{Corresponding authors:}

Ihosvany Camps (icamps@unifal-mg.edu.br)

Wilmar Puma-Zamora (070994@unsaac.edu.pe) 


\section{ABSTRACT}

The rapid global spread of SARS-CoV-2, the causative agent of COVID-19, has set off the alarms of healthcare systems all over the world, the situation is exacerbated as no effective treatment is available to date. One therapeutic strategy consists in stopping the replication of the virus by inhibiting SARS-CoV-2 main protease, an important enzyme in the processing of polyproteins from viral RNA. Applying techniques like virtual screening, molecular docking and molecular dynamics simulations, our study evaluated the biomolecular interactions generated between more than 200 thousand natural products structures collected from the Universal Natural Product Database and the main protease active site. Through successive docking filters, we identified 3 molecules with a good affinity profile for the enzyme. These were subjected to molecular dynamics simulations and their binding free energies were calculated. Structures of the best natural products identified could be a starting point for developing novel antiviral candidates targeting SARS-CoV-2 $\mathrm{M}^{\text {pro }}$.

Keywords: SARS-CoV-2 M $\mathrm{M}^{\text {pro }}$, natural products, virtual screening, molecular docking, molecular dynamics simulations

\section{ABBREVIATIONS}

$42 \quad \mathrm{M}^{\text {pro }} \quad$ : SARS-CoV-2 Main protease

43 COVID-19 : Coronavirus disease-19

44 SARS-CoV-2 : Severe acute respiratory syndrome coronavirus 2

45 UNPD : Universal Natural Product Database

46 UNPD-ISDB : Universal Natural Product Database - In-Silico MS/MS DataBase

47 IFD : Induced Fit Docking

48 VS : Virtual Screening

49 RMSD : Root Mean Square Deviation

50 RMSF : Root Mean Square Fluctuation

$51 \mathrm{Rg} \quad$ : Radius of Gyration

52 NPs : Natural products

53 MDS : Molecular Dynamics Simulations

54 MM-GBSA : Molecular Mechanics - Generalized Born Surface Area

55 PR : Phillyraeoidin E

56 PHF : Pseudoheptafuhalol-C

57 GPA : [28-(beta-d-glucopyranosyloxy)-28-oxoolean-12-en-3-beta-Yl]

\section{INTRODUCTION}

On December 12, 2019, a patient with apparent signs of acute respiratory disease, vitreous opacity in pulmonary X-rays, hypoxia, and impaired kidney and liver functions entered the Central Hospital of Wuhan, Hubei, People's Republic of China (F. Wu et al., 2020). By January 11, 2020, the number of patients rose to 41, all of them related to Wuhan's Huanan Seafood Wholesale Market, which also sold wild animals for human consumption. Chinese health authorities indicated that patients were tested negative for viruses and bacteria typically associated with respiratory diseases, but they were however subsequently tested positive for a new pathogen of the genus betacoronavirus (Chen et al., 2020). Once its genome was 
sequenced, the new virus (formerly known as 2019-nCoV) was named by WHO as Severe Acute Respiratory Syndrome Coronavirus 2 (SARS-CoV-2) (Chen et al., 2020; Lu et al., 2020) and later the disease was named Coronavirus Disease 2019 (COVID-19) (World Health Organization, 2020b).

Despite the enormous efforts of the Chinese government to control SARS-CoV-2 within its borders, it spread to 114 countries, infected 118,000 people and caused the deaths of 4,219, urging the WHO to declare COVID-19 as a global emergency, and subsequently as a pandemic (WHO Director-General's Conference, 2020). By September 29, 2020, the disease has already spread around the world with an estimated total of 33,511,752 cases and 1,004,808 deaths (COVID-19 Map, 2020).

Transmission of SARS-CoV-2 occurs through close contact between a carrier and a healthy individual as the virus spreads in droplets when coughing, sneezing, talking or singing (World Health Organization, 2020a). The average incubation period for COVID-19 is around 7 days, considering the interquartile range from 2 to 7 days (Guan et al., 2020). Moreover, it was estimated that an asymptomatic person carrying the virus can be contagious for 2 to 3 days before developing any symptoms and up to $44 \%$ of disease transmission cases occurred during the asymptomatic stage (He et al., 2020). This evidence explains the rapid spread of SARS-CoV-2 around the globe (Paules et al., 2020).

SARS-CoV-2 is a positive-strand RNA virus wrapped in a lipid bilayer, which fuses with the host cell, releasing its genetic material to the cytoplasm in order to express its viral proteins and replicate its genome, assembling itself into new viruses which will be released from the host cell (Lu et al., 2020; Qinfen et al., 2004; F. Wu et al., 2020). His RNA contains 10 open reading frames (ORFs) that encode a variety of viral proteins (Lu et al., 2020). ORF1ab encodes a polyprotein (PP) that contains non-structural proteins (NSP) involved in the replication and transcription of viral RNA. In addition, they contain two important proteases for fragmentation of PP1ab in 14 regions. The other ORFs (2 to 10) encode structural and auxiliary proteins (Lu et al., 2020; C. Wu et al., 2020). Within the proteome of the SARS-CoV-2, it is worth highlighting the importance of the protease NSP5 for the release of other functional proteins involved in replication and transcription of viral RNA (Muramatsu et al., 2016; Ratia et al., 2008; C. Wu et al., 2020).

This NSP5 is a 3-chymotrypsin-like cysteine protease, $3 \mathrm{CL}^{\text {pro }}$, also known as main protease ( $\left.\mathrm{M}^{\text {pro }}\right)$. It is an enzyme composed of 306 amino acids with a theoretical isoelectric point of 5.95 and an aliphatic index of 82.12 (Tahir ul Qamar et al., 2020). Its main function is to hydrolyze PP1ab in at least 11 conserved sites, releasing the NSP4 proteins to NSP16 (Jin et al., 2020; Yang et al., 2005). Its sequence shares $96.08 \%$ identity with its SARS-CoV counterpart, with twelve mutation points (Val35Thr, Ser46Ala, Asn65Ser, Val86Leu, Lys88Arg, Ala94Ser, Phe134His, Asn180Lys, Val202Leu, Ser267Ala, Ser284Ala and Leu286Ala). However, both proteins conserve the catalytic dyad residues His41 and Cys145. Except for the Leu286Ala mutation, all other mutations retain their polar or hydrophobic properties (Tahir ul Qamar et al., 2020).

At the structural level, the SARS-CoV-2 $\mathrm{M}^{\text {pro }}$ (hereafter referred to as $\mathrm{M}^{\mathrm{pro}}$ ) monomer has three domains: domain I (residues 8-101), domain II (residues 102-184), domain III (residues 201-303) and a loop (residues 185-200) that connects

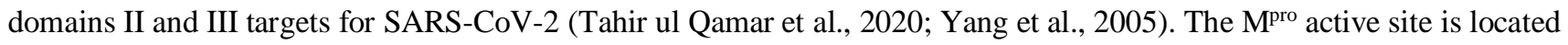
in an opening between domain I and II, which contains both catalytic residues (Mirza \& Froeyen, 2020; Tahir ul Qamar et al., 2020; Yang et al., 2005). In addition, close to the active site, three important subsites S1, S2 and S4 have been identified for substrate recognition together with the Tyr161 and His163 residues, forming the substrate-binding pocket (Yang et al., 2005). The substrate recognition sequence is Leu-Gln*(Ser, Ala, Gly) (where * marks the cleavage site) and no human proteases have been found with a similar cleavage sequence (Zhang et al., 2020), and even more, this viral enzyme does not 
106

107

108

109

110

111

112

113

114

115

116

117

118

119

120

121

122

123

124

125

126

127

128

129

130

131

132

133

134

135

136

137

138

139

140

141

142

143

144

have related homologous in humans (Jin et al., 2020). Therefore, potential inhibitory molecules would have a preference for the $\mathrm{M}^{\text {pro }}$ substrate recognition region.

The rapid transmission of this coronavirus has caused global healthcare systems to face a daunting challenge, where social isolation and lockdowns implementation have been the first containment strategy (Karnon, 2020). Although lockdowns have significantly slowed down the transmission of SARS-CoV-2, they are not sustainable long-term strategies (Endstrasser et al., 2020; Thakur et al., 2020). For this reason, the scientific community has started a race against the clock, focusing their efforts on the search for efficient vaccines or drugs for effective treatment against COVID-19 (Arnold, 2020; Khuroo et al., 2020; Sharma \& Surani, 2020).

In response to the global emergency, many institutions are conducting clinical trials applying the drug repurposing technique (National Institutes of Health, 2020) and also pre-clinical studies with natural compounds (Khalifa et al., 2020) in order to find potential antivirals against SARS-CoV-2. In this way, medicinal plants are a key part of the history of humanity because they are a source of phytochemical compounds with therapeutic activity, and these compounds were and are used as lead compounds to develop drugs (Gu et al., 2013). In an effort to gather information on phytochemicals reported in various plants around the world, the Universal Natural Product Database (UNPD) was created (Gu et al., 2013), which is currently available in a mirror version, as the UNPD In-Silico MS/MS Database (UNPD-ISDB) (Allard et al., 2016) containing 213,210 molecular structures of NPs and freely available at http://oolonek.github.io/ISDB.

To accelerate the search for molecules with therapeutic potential, many research groups around the world are using techniques like molecular docking in virtual screening (VS) assays from compounds libraries to identify molecules which are most likely to bind to a drug target, and complementing with molecular dynamics simulations (MDS) to analyze the conformational dynamics of proteins under conditions that mimic biological systems (Lin et al., 2020). With this objective, these tools were used to evaluate the inhibitory potential of natural products (NPs) (C et al., 2020; Ibrahim et al., 2020; Majumder \& Mandal, 2020; Mazzini et al., 2020; Oso et al., 2020; Rao et al., 2020; Sayed et al., 2020; Sen et al., 2020), approved drugs (Gurung et al., 2020; Jiménez-Alberto et al., 2020; Kandeel \& Al-Nazawi, 2020) and both of them (Fischer et al., 2020; Gentile et al., 2020; Kanhed et al., 2020) against $\mathrm{M}^{\text {pro. }}$. The results of these projects show compounds that could be used for in vitro tests to verify their antiviral activity or optimize their structures to improve their affinity for the enzyme.

Despite the efforts of the scientific community, until now there are no vaccines or drugs for a definitive treatment against COVID-19, and the discovery and development of new therapeutic agents is a long and expensive process (DiMasi et al., 2016). Therefore, computational tools such as the ones performed in this project can be used to predict the binding mode of ligands in the active site of interest and analyze the stability of a ligand-receptor complex under simulated biological conditions. Although computational techniques do not replace in vitro or in vivo tests, they offer a high throughput tool towards the discovery and development of efficient compounds (Lin et al., 2020).

Keeping this in mind, our study aims to identify important biomolecular interactions between the NPs reported in the UNPD-ISDB and $\mathrm{M}^{\text {pro }}$ active site residues through VS, molecular docking and MDS.

\section{MATERIALS AND METHODS}

\subsection{Overview of procedures used for selecting the NPs with the best affinity for $M^{\text {pro }}$}

In order to obtain ligands with the best ability to interact with residues of the active site of $\mathrm{M}^{\text {pro }}$, the workflow had several steps. We used 213,038 molecules of the UNPD-ISDB without any filtering. Previously we carried out the 
145

146

147

148

149

150

151

152

153

154

155

156

157

158

159

160

161

162

163

164

165

166

167

168

169

170

validation of VS and molecular docking protocols by redocking the co-crystallized ligand of $\mathrm{M}^{\text {pro }}$. Then, a VS was performed with the AutoDock Vina v1.1.2 software (also referred to as Vina) (Trott \& Olson, 2009). Based on the binding affinity values reported by Vina, the best 1000 compounds were docked using ligand flexible and rigid receptor with Schrödinger's Glide module (Friesner et al., 2004) in standard precision (Glide-SP) and extra precision (Glide-XP) mode. The hits from the Glide-XP step were docked with the Induced Fit Docking (IFD) protocol (Sherman et al., 2006), that allows flexibility to the ligands and residues that are within the volume of the search box. The VS with the subsequent molecular docking was made to give reliability to the results (Berry et al., 2015; Lindert et al., 2015; Mirza \& Froeyen, 2020).

From these results, the 3 best hits were selected to perform molecular dynamics simulations with GROMACS (Abraham et al., 2015) v2020-2 to verify the stability of the 3 ligand-receptor complexes.

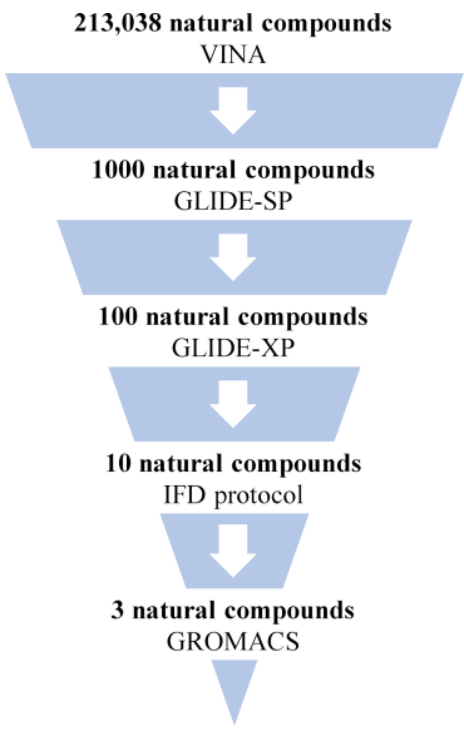

Figure 1. Workflow used to select potential $\mathrm{M}^{\text {pro }}$ inhibitors. The hits selection was based on the binding affinity value in the case of Vina, and the docking score in the case of Glide.

\subsection{Virtual screening and molecular docking}

\subsubsection{Receptor preparation}

A protein model was prepared for each process. For VS, the crystal structure of SARS-CoV-2 M ${ }^{\text {pro }}$ (PDB ID 6W63, 2.10 A) (Mesecar, 2020) was retrieved in PDB format from the Protein Data Bank (http://www.rcsb.org/) (Burley et al., 2019). Using the AutoDockTools-1.5.6 (Morris et al., 2009), all water molecules and ions were removed from the receptors. Polar hydrogens were added to the receptors (Musa et al., 2018; F. Wang et al., 2019) and the structure was saved in PDBQT format.

For molecular docking, the same protein retrieved from PDB was prepared using the Protein Preparation Wizard module (Madhavi Sastry et al., 2013) included in the Schrödinger suite. Also, all water molecules and ions were removed, and bond orders and explicit hydrogens were assigned to the structure (Nakladal et al., 2019). Protonation states at $\mathrm{pH} 7.4$ for residues 
171

172

173

174

175

176

177

178

179

180

181

182

183

184

185

186

187

188

189

190

191

192

193

194

195

196

197

198

199

200

201

202

203

204

205

206

207

208

209

were prepared by using PROPKA module (Olsson et al., 2011; Rostkowski et al., 2011) implemented in the Protein Preparation Wizard

\subsubsection{Ligands preparation}

For VS, the UNPD-ISDB was used as it is currently the unique available mirror of the original UNPD. Using the Open Babel v3.0.0 program (O’Boyle et al., 2011), NPs in linear InChI notation (Heller et al., 2015) were converted to threedimensional structures (Panda et al., 2020), minimized by 20 thousand steps with the MMFF94 force field and hydrogens at pH 7.4 (Gyebi et al., 2020; Tsuji, 2020) were added. The prepared ligands were then saved in PDBQT format ready for VS. In the preparation, 172 molecules were discarded because they had arsenic in their constitution, and this element is not parameterized in the MMFF94 force field (Halgren, 1996).

For molecular docking, the best 1000 hits of the VS were prepared with the LigPrep module (LigPrep, 2018) of Schrödinger suite, performing a geometric minimization with the OPLS_2005 force field and assigning appropriate ionization states at pH 7.4 (Sigalapalli et al., 2020).

\subsubsection{Virtual screening}

Vina was used to perform VS of the NPs database in $\mathrm{M}^{\text {pro }}$ active site. The optimal size of the search box (40x40x40 $\AA$ in $\mathrm{X}, \mathrm{Y}$ and $\mathrm{Z}$ axis, respectively), was calculated using the eBoxSize script (Feinstein \& Brylinski, 2015) and the coordinates of the centroid of $\mathrm{M}^{\text {pro }}$ binding site ( $\mathrm{x}=-20.7, \mathrm{y}=17.3, \mathrm{z}=-26.7$ ), which covered the catalytic dyad residues, were determined with the POCASA server (Yu et al., 2009). The calculations were performed in the Quinde 1 supercomputer (Imbabura, Ecuador) with an exhaustiveness level of 24.

We used all the UNPD-ISDB NPs structures without any filter, since the active site of $\mathrm{M}^{\text {pro }}$ has a tendency to undergo conformational changes that could not be stabilized by small inhibitors (Bzówka et al., 2020). In this way, high molecular weight NPs could be stabilized by more favorable biomolecular interactions with residues close to the active site.

\subsubsection{Molecular docking}

For increase the reliability of the results as shown in Figure 1, the best 1000 hits of VS with the best binding affinity values, after being prepared with LigPrep, were docked with Schrödinger's Glide module using Glide-SP. From the new results, Glide-SP's top 100 ligands with the best docking score were docked with Glide-XP. Steps with Glide-SP and Glide$\mathrm{XP}$ were done using flexible-ligand docking and rigid-receptor. Following, the top 10 hits from the Glide-XP step were docked with the IFD protocol, which performs an initial docking with Glide, then a relaxation of residues with Prime (Jacobson et al., 2004), and then a redocking of the ligands with Glide into the relaxed active site.

All molecular docking studies were performed with the OPLS_2005 force field applying the same centroid coordinates and box dimensions that were used for the VS. To analyze the non-covalent interactions of the 3 best hits of the IFD protocol, the LigPlot+ v.2.1 program was used (Laskowski \& Swindells, 2011).

\subsection{Molecular dynamics simulations (MDS)}

To evaluate the stability of the best three hits docked by IFD in the binding site of the $\mathrm{M}^{\text {pro }}$, MDS were performed with the GROMACS software v2020-2. The topology of the systems was built using the pdb2gmx module of the GROMACS software. Each complex was solvated in a cubic box at $10 \AA$ from the box edge using the explicit solvation model TIP3P 
210

211

212

213

214

215

216

217

218

219

220

221

222

223

224

225

226

227

228

229

230

231

232

233

234

235

236

237

238

239

240

241

242

243

244

245

246

247

(Jorgensen et al., 1983), applying PBC conditions and the OPLS_AA force field. Subsequently, $\mathrm{Na}^{+}$and $\mathrm{Cl}^{-}$ions were added to the solvent to neutralize the charges at a physiological concentration of $150 \mathrm{mM}$. The energy minimization of the system was carried out using the descending step algorithm, with 50,000 steps until obtaining forces of $<10.0 \mathrm{~kJ} / \mathrm{mol}$. Then, the system was equilibrated using an isochoric-isothermal ensemble (NVT) and a subsequent isothermal-isobaric ensemble (NPT) for 2 and $4 \mathrm{~ns}$, respectively. The temperature was maintained at $310 \mathrm{~K}$ with the Berendsen thermostat (Berendsen et al., 1984), while the pressure was at 1.0 bar with the Parrinello-Raman barostat (Parrinello \& Rahman, 1980). The LINCS algorithm (Hess et al., 1997) was used to restrict interactions with long-range electrostatic forces calculated using Ewald's mesh particle algorithm (Darden et al., 1993). For the calculation of short-range non-bonded interactions a cutoff ratio of $1.2 \mathrm{~nm}$ for Coulomb and van der Waals potentials were used. The simulation was performed during $200 \mathrm{~ns}$ with integration steps of 2 fs. Simulation trajectories obtained were used to analyze the root-mean-square deviation (RMSD), root mean square fluctuation (RMSF), radius of gyration $(\mathrm{Rg})$, solvent accessible surface area (SASA) and number of hydrogen bonds (H-bonds).

\subsection{Binding free energy calculations}

The binding free energy ( $\Delta \mathrm{G}_{\text {bind }}$ ) of the ligand-receptor complexes were calculated by the physic-based Molecular Mechanics - Generalized Born Surface Area (MM-GBSA) method (Genheden \& Ryde, 2015) with the Prime module using the continuum VSGB solvation model (Li et al., 2011) and OPLS_2005 force field. The $\Delta \mathrm{G}_{\text {bind }}$ was calculated by the following equation:

$\Delta \mathrm{G}_{\text {bind }}=\mathrm{G}_{\text {complex }}-\left(\mathrm{G}_{\text {protein }}+\mathrm{G}_{\text {ligand }}\right)$

Where $\mathrm{G}_{\text {complex }}, \mathrm{G}_{\text {protein }}$ and $\mathrm{G}_{\text {ligand }}$ are the free energy of the complex, protein and ligand, respectively. The ligandreceptor complexes were subjected to $\Delta \mathrm{G}_{\text {bind }}$ calculation. For this purpose, 20 snapshots were taken at $10 \mathrm{~ns}$ time intervals throughout the MDS trajectory to calculate the MM-GBSA free energy differences. As a control, $\mathrm{M}^{\text {pro }}$ was also simulated with its co-crystallized native ligand $X 77$. The results are presented as the average $\Delta \mathrm{G}_{\text {bind }} \pm$ standard deviation.

\section{RESULTS AND DISCUSSION}

\subsection{Validation of docking protocol}

To validate the molecular docking conditions, the co-crystallized ligand X77 was removed and re-docked applying the same parameters of box size and centroid coordinates, which corroborated the reliability of the parameters adopted by the program. This procedure was applied for the X77 co-crystallized $\mathrm{M}^{\text {pro }}$ ligand. Thus, after being re-docked and compared with its native crystallized conformation, it had an RMSD difference of $1.045 \AA$ when docked with Vina, $1.233 \AA$ with Glide-SP and $1.986 \AA$ with Glide-XP (Figure 2). According to the methodology reported in literature, a reliable molecular docking protocol is the one in which the RMSD difference between the best docked conformation and the crystallized native conformation of a ligand is $\leq 2.0 \AA$ ( $\mathrm{R}$. Wang et al., 2003). Therefore, the protocols used with Vina and Glide in our study are reliable and can be used to evaluate the interactions generated between the SARS-CoV-2 M ${ }^{\text {pro }}$ active site and NPs. 


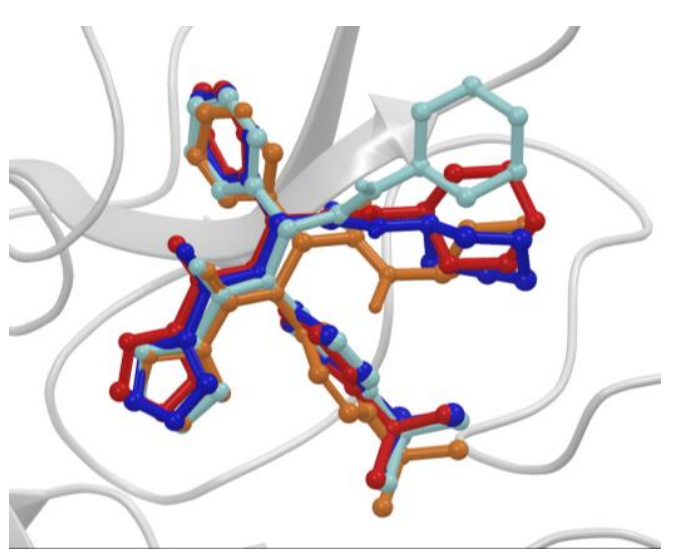

Figure 2. Results of the validation of the docking protocol in Mpro. The ligand X77 co-crystallized is shown in red, docked with Vina in blue, with Glide SP in cyan and with Glide XP in orange. As shown in all cases, RMSD difference values less than $2.0 \AA$.

\subsection{Virtual screening}

The results of the VS with Vina were grouped by binding affinity ranges of $1 \mathrm{kcal} / \mathrm{mol}$ versus the frequency of ligands that obtained such binding affinity values (Figure 3). Almost 36\% $(77,214)$ of all ligands were found to have a binding affinity between -7 to $-7.9 \mathrm{kcal} / \mathrm{mol}$. The 1000 top hits, with binding affinity values between -13.7 and $-10 \mathrm{kcal} / \mathrm{mol}$, were selected for further molecular docking analysis.

258

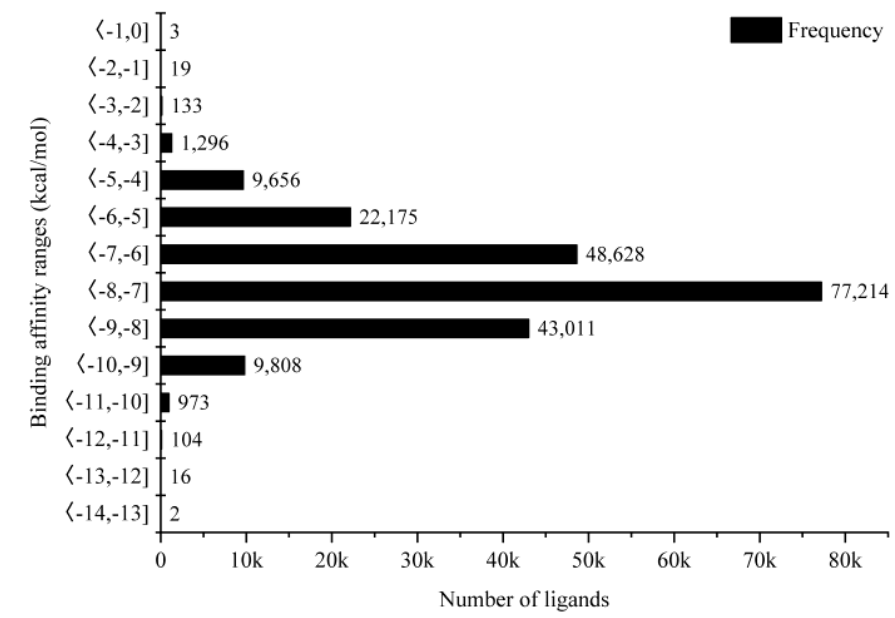

Figure 3. Screened NPs binding affinities distribution. The graph shows the ranges for binding affinity values versus the frequency of ligands that reached these binding affinity values. The ligands for the molecular docking analysis were selected according to the best binding affinity values.

\subsection{Molecular docking}

Vina's 1000 top hits were docked with Glide-SP, obtaining among the best 100 conformations of docking score energies from -7.872 to $-11.170 \mathrm{kcal} / \mathrm{mol}$. Following the working protocol, the 100 top hits of molecular docking with Glide-SP were docked with Glide-XP mode. Based on this step, the top 10 conformations gave docking score values between -3.147 and - 
269 best ligands were identified as phillyraeoidin E (PR), pseudoheptafuhalol-C (PHF) and [28-(beta-d-glucopyranosyloxy)-28-

270 oxoolean-12-en-3-beta-Yl]-2-O-beta-D-xylopyranosyl-3-O-alpha-L-rhamnopyranosyl-beta-D glucopyranosiduronic acid

271 (GPA). Table 1 shows the main energy components reported by the IFD module for each hit.

272 Ligands with better binding affinity are relatively large and under flexible ligand docking conditions, adopt a broad

273 conformational spectrum. Thus, an energetic stability of the NPs and the receptor was expected, dependent on the surface

274 area and short-distance biomolecular interactions. Table 2 shows that the ligands PR, PHF and GPA, acquire a high docking

275 score with IFD protocol due to H-bonds and hydrophobic interactions in the $\mathrm{M}^{\text {pro }}$ active site and other residues close to that

276 region. All 3 ligands interact with His41, while only PR and PHF interact with Cys145. These catalytic residues are of

277 interest for the inhibition of $\mathrm{M}^{\text {pro }}$ activity. PR was docked with 15 of the 25 amino acids in the pocket and presents a

278 docking score of $-20.9 \mathrm{kcal} / \mathrm{mol}$, obtained mainly by $20 \mathrm{H}$-bonds, where the oxygen atom O9, stands out (Figure 4a), due to

279 its 4 H-bonds in the region polarized by Arg188, Thr190 and Gln192. On the other hand, hydrophobic interactions with PR

280 occur with the residues Thr25, Met49 and Leu50, with Thr25 being relevant because it also interacts with PHF and GPA.

281 PHF (Figure 4b) interacts with 15 amino acids, where 13 are by H-bond and 6 by hydrophobic interactions. Finally, GPA

282 (Figure 4c) interacts with 14 amino acids, with 13 due to H-bond and 5 due to hydrophobic interactions.

283 Interestingly, a recent study (Gentile et al., 2020) detected phlorotannins structurally similar to PHF and with great

284 binding affinity for the $\mathrm{M}^{\text {pro }}$ active site. These were also present in the brown algae Sargassum spinuligerum. According to

285 literature, several species of algae belonging to the Sargassum family have been used in traditional Chinese medicine as

286 therapy against cancer, inflammations, bacteria and viruses (Liu et al., 2012). Such algae could thus be worth further

287 investigations concerning their potential interest to fight SARS-CoV-2 infections. 
289 Table 1. Information about the three top NPs from the IFD analysis.

\begin{tabular}{|c|c|c|c|c|c|}
\hline Name & UNPD-ISDB ID & Common name & Structure & Compound class & Biological source \\
\hline PR & 158047 & Phillyraeoidin E & & Tannin & $\begin{array}{l}\text { Quercus phillyraeoides } \\
\text { (Nonaka et al., 1989) }\end{array}$ \\
\hline & & & & & $\begin{array}{c}\text { Sargassum spinuligerum } \\
\text { (Keusgen \& Glombitza, 1997) }\end{array}$ \\
\hline & & & & & $\begin{array}{l}\text { Carpophyllum angustifolium } \\
\text { (Glombitza \& Schmidt, 1999) }\end{array}$ \\
\hline GPA & 121581 & N/A & & Prenol lipids & $\begin{array}{l}\text { Dumasia truncata } \\
\text { (Kinjo et al., 1995) }\end{array}$ \\
\hline
\end{tabular}

Table 2. Main energy components of docking score reported by IFD module and interacting residues reported by LigPlot+.

\begin{tabular}{|c|c|c|c|c|c|c|}
\hline \multirow[b]{2}{*}{ Name } & \multirow[b]{2}{*}{$\begin{array}{c}\text { Docking score } \\
\text { (kcal/mol) }\end{array}$} & \multicolumn{3}{|c|}{ Main energy components (kcal/mol) } & \multicolumn{2}{|c|}{ Interacting residues } \\
\hline & & H-bonds & $\begin{array}{l}\text { Lipophilic } \\
\text { EvdW }\end{array}$ & $\begin{array}{l}\text { Electrostatic } \\
\text { interactions }\end{array}$ & $\begin{array}{c}\text { H-bonds } \\
\text { interactions }\end{array}$ & $\begin{array}{l}\text { Hydrophobic } \\
\text { interactions }\end{array}$ \\
\hline PHF & -19.28 & -10.81 & -7.41 & -2.00 & $\begin{array}{c}\text { Thr24, Thr26, Met49, Tyr118, } \\
\text { Asn412, Cys145, His163, His164, } \\
\text { Glu166 }\end{array}$ & $\begin{array}{l}\text { Thr25, His41, Leu141, } \\
\text { Met165, Pro168, Gln189 }\end{array}$ \\
\hline GPA & -19.25 & -10.89 & -6.69 & -1.99 & $\begin{array}{l}\text { His41, Asn119, Asn142, Gly143, } \\
\text { Glu166, Arg188, Gln189, Thr190, } \\
\text { Gln192 }\end{array}$ & $\begin{array}{c}\text { Thr25, Thr26, Met49, } \\
\text { Met165,Asp187 }\end{array}$ \\
\hline
\end{tabular}




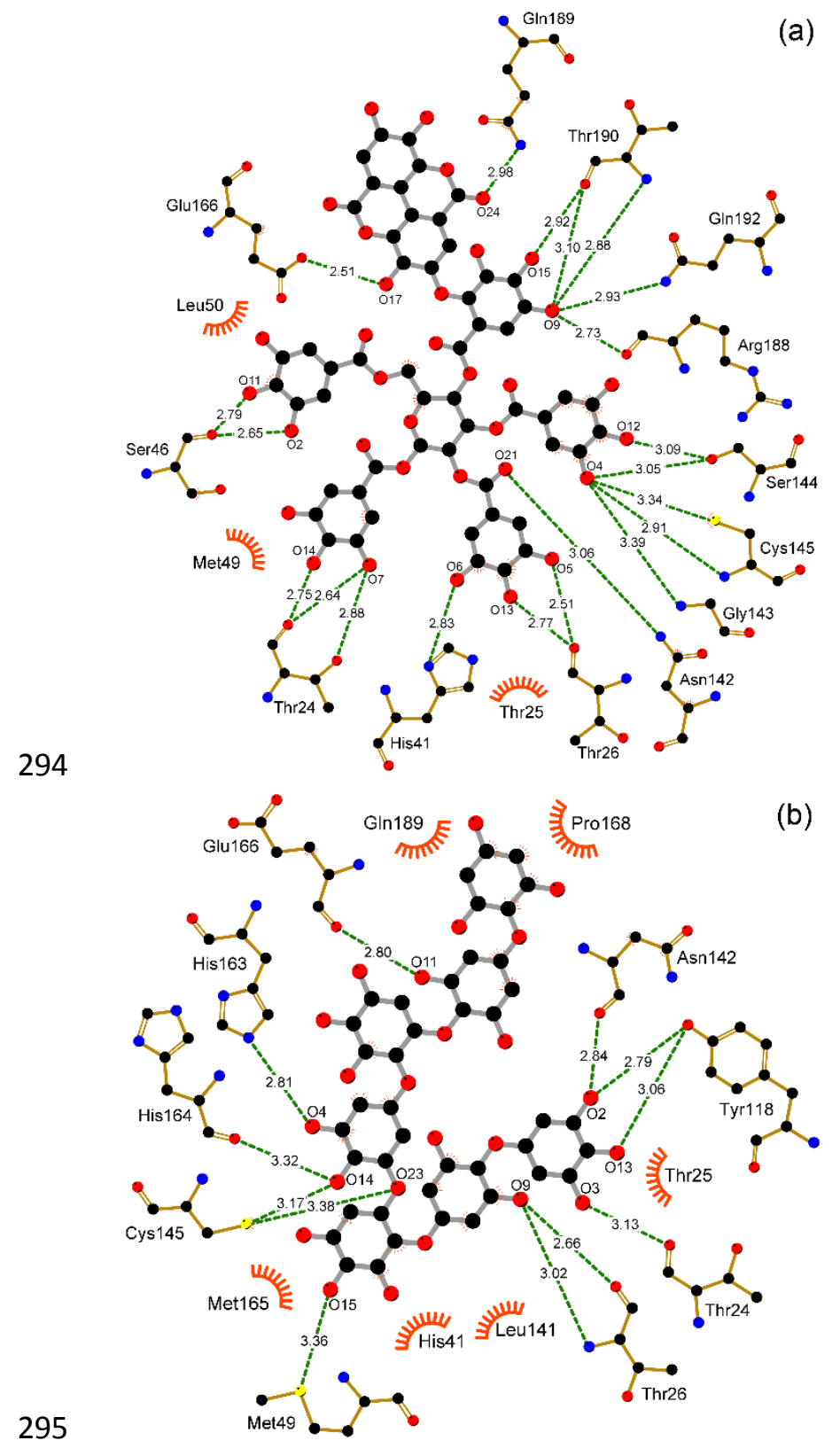


296

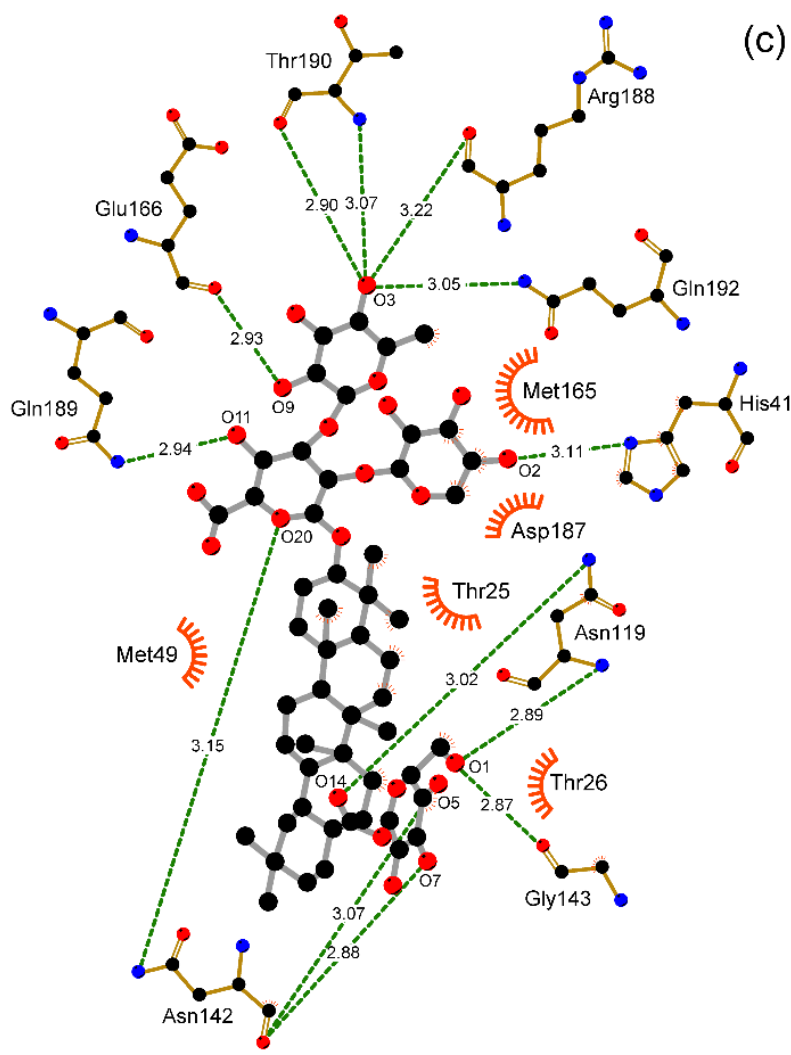

(c)

Figure 4. 2D interaction diagram of (a) PR, (b) PHF and (c) GPA with the $\mathrm{M}^{\text {pro }}$ active site. The dotted green lines represent H-bonds and their distances in Angstroms. The diagrams were generated with LigPlot+ v.2.1.

\subsection{Molecular dynamics simulations (MDS)}

MDS were performed to analyze the stability of the 3 complexes with the best IFD docking score values, and the $\mathrm{M}^{\text {pro }}$ with its native ligand X77 was considered as control. Table 3 shows the average values for the various parameters calculated using MDS. The Origin software (Seifert, 2014) was used to generate the plots. Molecular dynamics trajectories are presented as movies in supplementary material.

Table 3: Average values of RMSD, RMSF, Rg, SASA and number of H-bonds of the $\mathrm{M}^{\text {pro-ligand complexes calculated }}$ from MDS.

\begin{tabular}{|c|c|c|c|c|c|}
\hline \multirow{2}{*}{ Complex } & \multicolumn{5}{|c|}{ Average values \pm SD } \\
\cline { 2 - 6 } & $\mathbf{R M S D}(\mathbf{A})$ & $\mathbf{R M S F}(\mathbf{\AA})$ & $\mathbf{R g}(\mathbf{A})$ & SASA $\left(\mathbf{(}^{2}\right)$ & H-bonds \\
\hline $\mathrm{M}^{\mathrm{pro}}-\mathrm{X} 77$ & $1.82 \pm 0.29$ & $1.22 \pm 0.58$ & $21.92 \pm 0.14$ & $145.50 \pm 2.45$ & $1.89 \pm 0.42$ \\
\hline $\mathrm{M}^{\mathrm{pro}}-\mathrm{PR}$ & $2.84 \pm 0.42$ & $1.40 \pm 0.48$ & $22.01 \pm 0.11$ & $147.69 \pm 2.21$ & $6.49 \pm 1.96$ \\
\hline $\mathrm{M}^{\mathrm{pro}}-\mathrm{PHF}$ & $3.31 \pm 0.65$ & $2.00 \pm 0.78$ & $22.21 \pm 0.27$ & $150.33 \pm 2.49$ & $5.70 \pm 0.83$ \\
\hline $\mathrm{M}^{\mathrm{pro}}-\mathrm{GPA}$ & $2.03 \pm 0.32$ & $1.16 \pm 0.49$ & $21.78 \pm 0.13$ & $145.76 \pm 2.48$ & $5.11 \pm 2.00$ \\
\hline
\end{tabular}

\subsubsection{Root-mean-square deviation (RMSD)}

RMSD is an essential criteria to quantify the structural stability of a protein from its initial to final conformation within a time frame. For this work, the $\mathrm{M}^{\text {pro }}$ backbone RMSD of each complex was calculated (Figure 5). The average values for 
RMSD $\mathrm{M}^{\text {pro }}$ backbone in complex with ligands and co-crystallized ligand X77 are shown in Table 3. According to the

313 Figure 5, the $\mathrm{M}^{\text {pro }}$ backbone RMSD in complex with GPA and their native ligand X77, reach equilibrium almost from the beginning, although both experience a small fluctuation between $130-140 \mathrm{~ns}$, after which they regain their stability until the simulation is finished. Similarly, the $\mathrm{M}^{\text {pro }}$ backbone RMSD in complex with PR is seen, where it increases to $\sim 90 \mathrm{~ns}$ and then stabilizes. The $\mathrm{M}^{\text {pro }}$ backbone RMSD with the PHF ligand is the most unstable of all complexes, with peaks close to 5 $\AA$, suggesting that PHF increases the instability of the $\mathrm{M}^{\text {pro }}$.

318

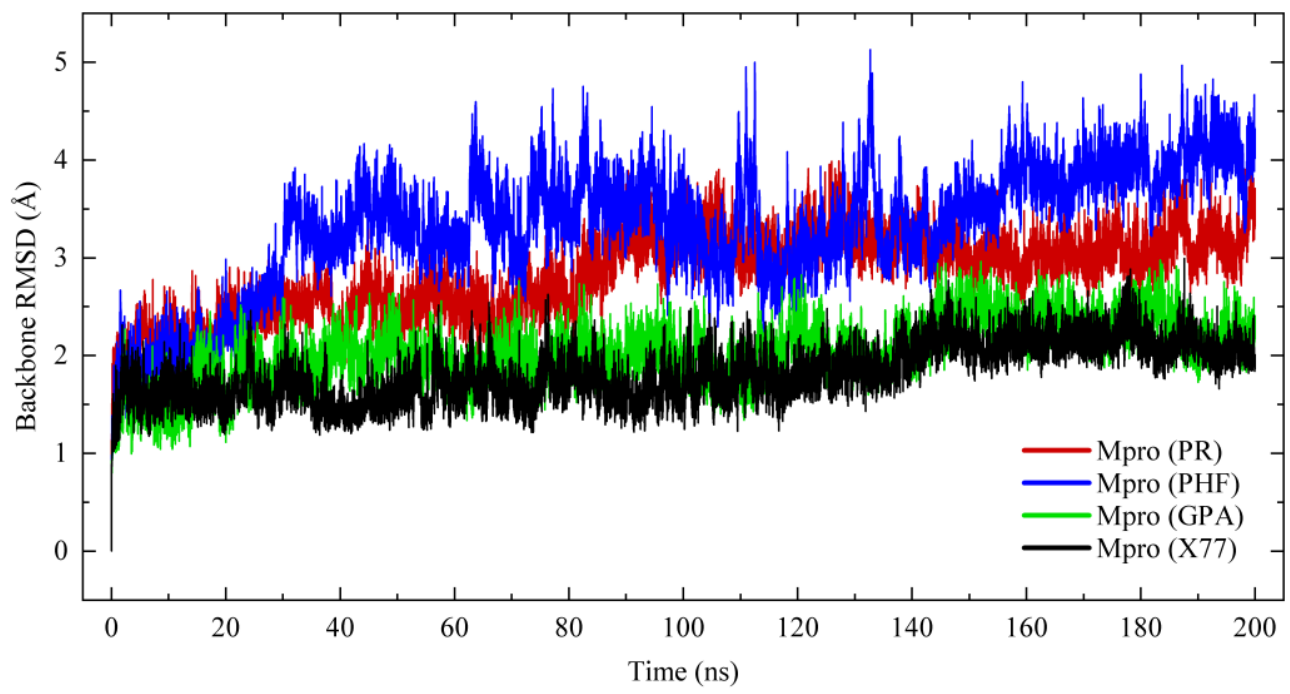

319

320

321

322

323

324

325

326

327

328

329

330

331

332

Figure 5. $\mathrm{M}^{\text {pro }}$ backbones RSMD over the simulation time.

\subsubsection{Root-mean-square fluctuation (RMSF)}

The RMSF was evaluated to identify the flexible or rigid regions of the protein structure, also this parameter can be used to inspect the flexibility of the residues. The Figure 6 shows the average backbone RMSF calculated for every residue throughout the simulation period. The mean RMSF values of $\mathrm{M}^{\text {pro }}$ and their ligands are shown in Table 3. We see that the average flexibility of $\mathrm{M}^{\text {pro }}$ is reduced when it is bound to the GPA ligand (1.16 $\pm 0.49 \AA$ ), even less than when its native ligand X77 (1.22 $\pm 0.58 \AA)$ is bound, which suggests that the GPA ligand would grant more rigidity to the enzyme. The mean RMSF value with the PR ligand reaches a value close to $(1.40 \pm 0.48 \AA)$ that does not differ significantly from the control $\mathrm{M}^{\text {pro }}$-X77 complex, but in the case of the complex with PHF, this ligand generates fluctuations in various regions of the $\mathrm{M}^{\text {pro }}$. The catalytic residues His41 $(0.83 \pm 0.15 \AA)$ and Cys145 $(0.73 \pm 0.13 \AA)$ show minimal fluctuations in the 4 complexes, which is why they remain quite stable throughout the simulation. 
333

334

335

336

337

338

339

340

341

342

343

344

345

346

347

348

349

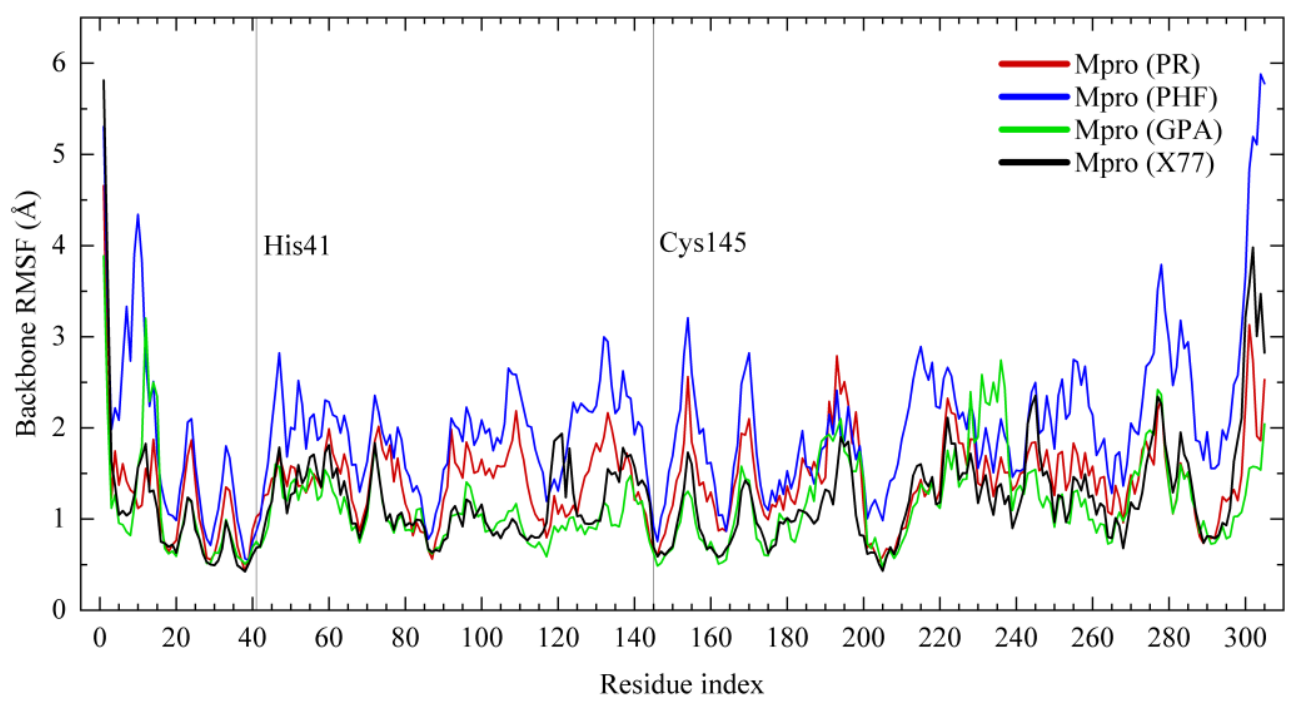

Figure 6. $\mathrm{M}^{\text {pro }}$ backbones RSMF over the simulation time.

\subsubsection{Radius of gyration $(\mathrm{Rg})$}

The Rg generally is defined as the mass weighted root mean square distance of a group of atoms from their center of mass

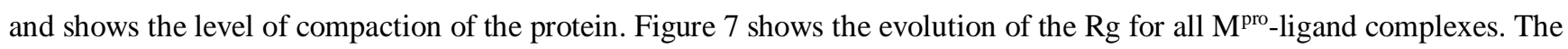
Rg average value for $\mathrm{M}^{\text {pro }}-\mathrm{PR}, \mathrm{M}^{\text {pro }}-\mathrm{PHF}, \mathrm{M}^{\text {pro }}-\mathrm{GPA}$ and the control $\mathrm{M}^{\text {pro }}-\mathrm{X} 77$ were found to be $22.01 \pm 0.11 \AA$, $22.21 \pm$ $0.27 \AA, 21.78 \pm 0.13 \AA$ and $21.92 \pm 0.14 \AA$ A respectively. The $\mathrm{M}^{\text {pro }}-$ GPA complex shows the lowest average Rg value, even slightly less than the $\mathrm{M}^{\text {pro }}$-X77 control, suggesting that the $\mathrm{M}^{\text {pro }}$ forms a more stable complex with the GPA. In the same way, the average value for $\mathrm{M}^{\text {pro }}-\mathrm{PR}$ complex exhibit similar rigidity as $\mathrm{M}^{\text {pro }}-\mathrm{GPA}$ and control $\mathrm{M}^{\text {pro }}-\mathrm{X} 77$. While the $\mathrm{M}^{\text {pro }}$ in complex with the PHF ligand maintains a stable Rg up to $90 \mathrm{~ns}$ from which it experiences fluctuation, suggesting that the PHF induces a loss of rigidity of the $\mathrm{M}^{\mathrm{pro}}$.

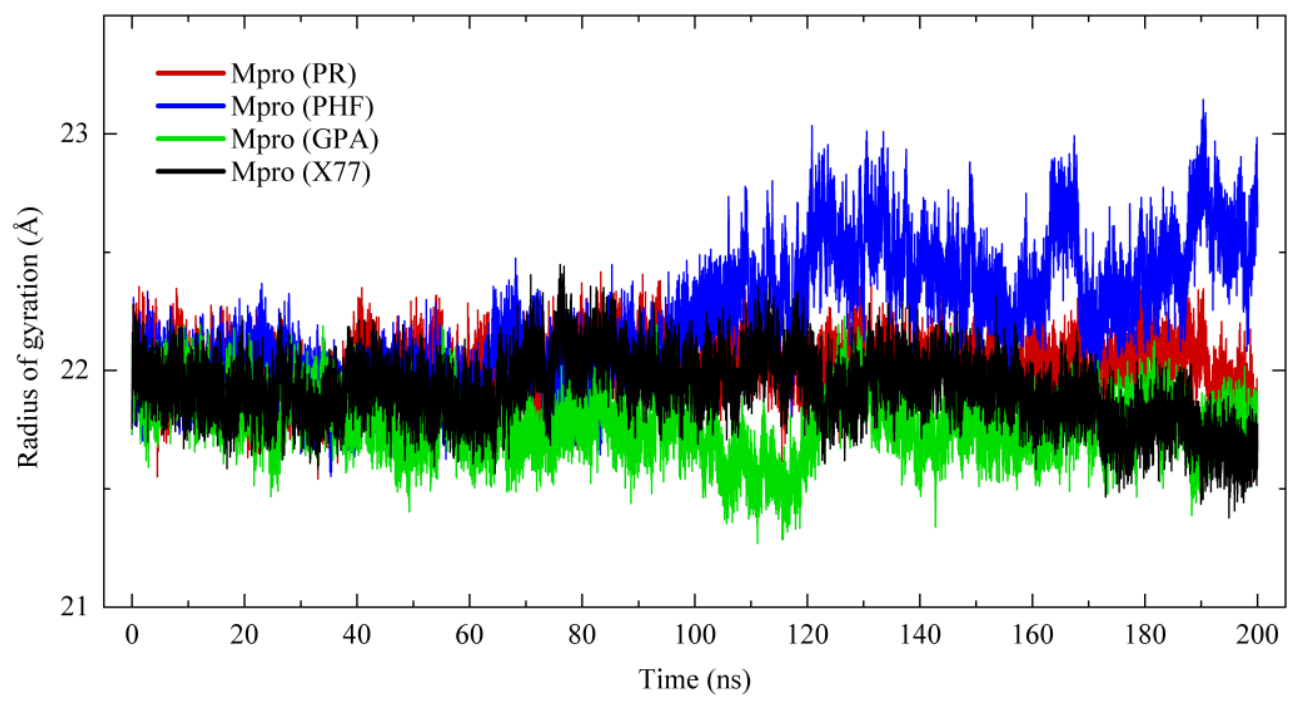

Figure 7. $\mathrm{Rg}$ for the $\mathrm{M}^{\text {pro }}$ from every complex over the simulation time. 


\subsubsection{Solvent accessible surface area (SASA)}

SASA was calculated for the $\mathrm{M}^{\text {pro }}$ in every complex as shown Figure 8. This analysis is useful to understand the hydrophilic-hydrophobic behaviour of a protein structure or protein-drug complexes. Higher SASA protein values indicate the expansion of the $\mathrm{M}^{\text {pro }}$ structure, so small fluctuations are expected during simulation. According to the average SASA values for proteins in Table 3, the $\mathrm{M}^{\text {pro }}$ in complex with the GPA ligand shows the average SASA value $\left(145.76 \pm 2.48 \AA^{2}\right)$ almost comparable to the $\mathrm{M}^{\text {pro }}$ bound to its native ligand X77 $\left(145.50 \pm 2.45 \AA^{2}\right)$ so these ligands would reduce the expansion of $\mathrm{M}^{\text {pro }}$; while when the protein binds to the PHF ligand, the SASA value increases $\left(150.33 \pm 2.49 \AA^{2}\right)$, which would indicate that the PHF would induce an expansion in the protein structure, increasing the solvent accessible surface of the $\mathrm{M}^{\text {pro }}$. This assessment is apparently correctly associated with the previous analysis of $\mathrm{Rg}$.

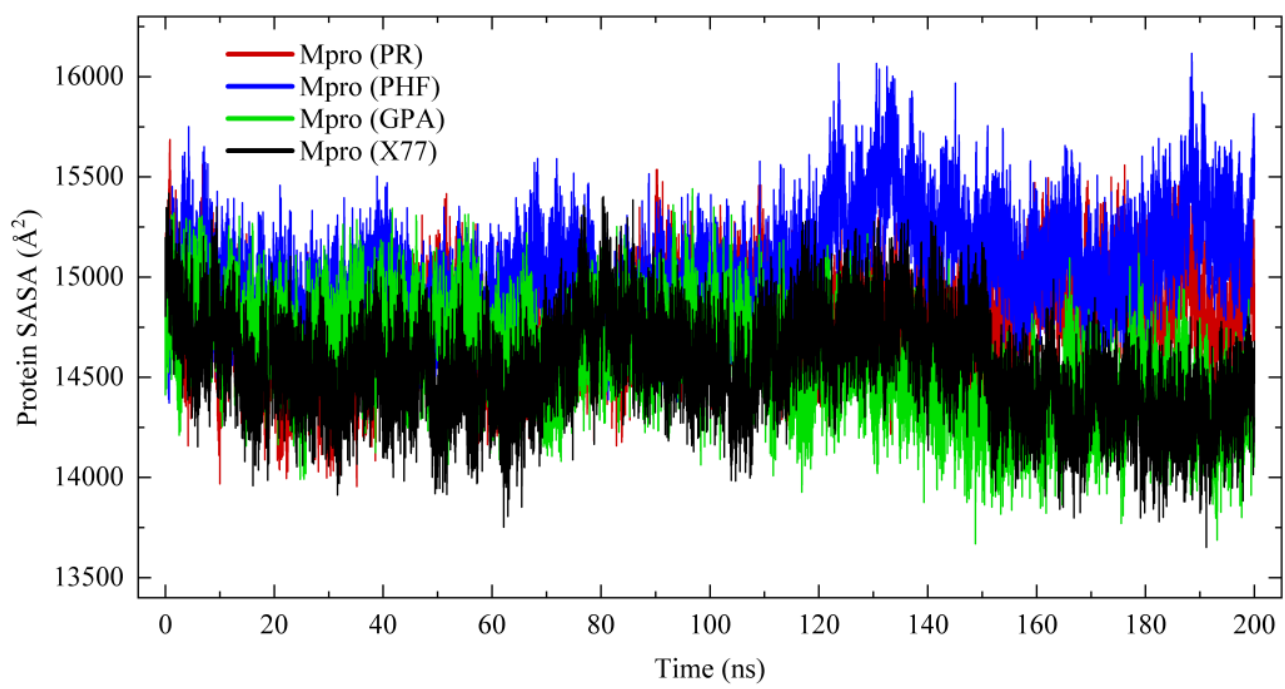

Figure 8. SASA analysis of $\mathrm{M}^{\text {pro }}$ from every complex over the simulation time.

\subsubsection{Ligand-receptor hydrogens bonds (H-bonds)}

$\mathrm{H}$-bonds generated between the $\mathrm{M}^{\text {pro }}$ and their ligands is a useful parameter to understand the affinity of the NPs towards a protein structure. Several H-bonds present in a ligand-receptor complex suggest a strong union. Due to the amount of hydroxyl groups in the molecular structures of the best hits, all of them presented several H-bonds throughout the simulation (Figure 9), surpassing the native ligand X77 (1.89 \pm 0.42$)$. Thus, those who exhibit a greater number of H-bonds were PR $(6.49 \pm 1.96)$, PHF $(5.70 \pm 0.83)$ and GPA $(5.11 \pm 2.00)$. This suggests that despite slightly destabilizing the enzyme, PHF and PR ligands remain attached to residues of the $\mathrm{M}^{\text {pro }}$ active site through $\mathrm{H}$-bonds. 


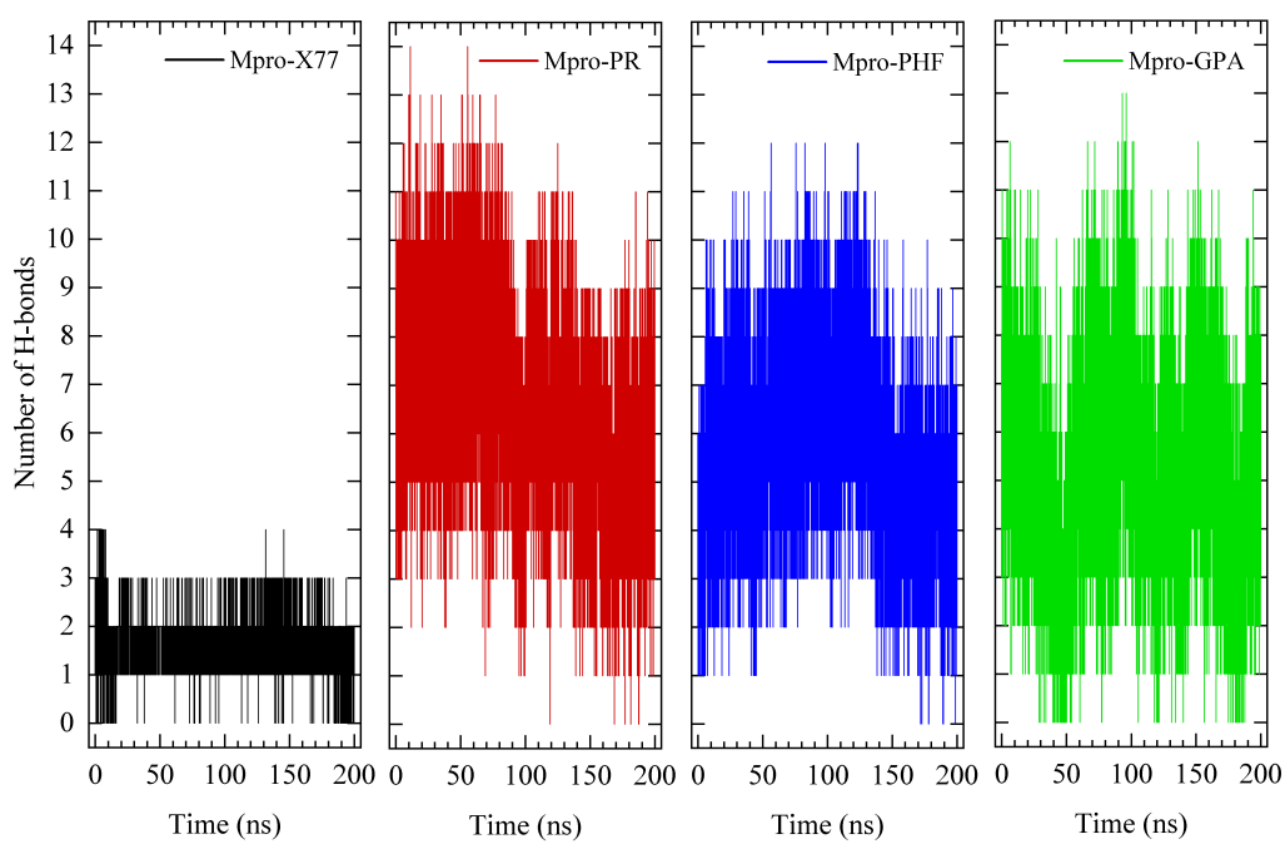

Figure 9. Number of $\mathrm{H}$-bonds between $\mathrm{M}^{\text {pro }}$ and their ligands during the simulation period.

\subsection{Free binding energy calculations}

The four complexes were subjected to ligand-receptor $\Delta \mathrm{G}_{\text {bind }}$ MM-GBSA analysis, for every $10 \mathrm{~ns}$ snapshots. The results shown in table 4 suggest that the NPs have an average $\Delta \mathrm{G}_{\text {bind }}$ higher than the control X77 $(-66.39 \pm 5.65 \mathrm{kcal} / \mathrm{mol})$ in all the cases. This could be due to the many hydroxyl groups that the ligands have and hydrophobic interactions, which would help stabilize the NPs with residues in the $\mathrm{M}^{\text {pro }}$ active site. Interestingly, it is observed that the ligand with less average $\Delta \mathrm{G}_{\mathrm{bind}}$ is PHF, which altered the stability with $\mathrm{M}^{\text {pro }}$ according to the RMSD, Rg and SASA analyzes. These results suggest that the NPs would have superior stability to the co-crystallized ligand $\mathrm{M}^{\text {pro-X77. }}$

Table 4. $\Delta \mathrm{G}_{\mathrm{bind}}$ values in $\mathrm{kcal} / \mathrm{mol} \pm \mathrm{SD}$, calculated by MM-GBSA for all the complexes.

\begin{tabular}{cccc}
\hline $\mathbf{M}^{\text {pro }}-\mathbf{X 7 7}$ & $\mathbf{M}^{\text {pro }}-\mathbf{P R}$ & $\mathbf{M}^{\text {pro }}-\mathbf{P H F}$ & $\mathbf{M}^{\text {pro }}-\mathbf{G P A}$ \\
\hline$-66.39 \pm 5.65$ & $-121.41 \pm 12.13$ & $-94.67 \pm 9.54$ & $-120.88 \pm 10.90$ \\
\hline
\end{tabular}

\section{CONCLUSIONS}

COVID-19 is an infectious disease that to date, does not have a vaccine or antiviral with proven efficacy. Therefore, taking into consideration the outstanding track record of NPs as efficient drug candidates, we performed an extensive in silico evaluation of specialized metabolites reported in the literature to assess and understand the biomolecular interactions generated between these compounds and the active site of $\mathrm{M}^{\text {pro }}$. VS allowed for rapid filtering based on binding affinity, while molecular docking refined the results through successive steps, thus verifying the affinity between NPs and important $\mathrm{M}^{\text {pro }}$ residues. After an initial VS with Vina, post-filtering of results and docking with Glide using standard and extra precision, three NPs were selected: two tannins, phillyraeoidin-E (PR), pseudoheptafuhalol-C (PHF) and a triterpenoidal saponin (GPA). They were subjected to MDS to verify their stability over $200 \mathrm{~ns}$, resulting in two of them (PR and GPA) with a better conformational stability and energetic profile than the co-crystallized ligand X77 of the enzyme. Finally, the 
394

395

396

397

398

399

400

401

402

403

404

405

406

407

408

409

410

411

412

413

414

415

416

417

418

419

420

421

422

423

424

425

426

427

428

429

430

431

432

affinity of the selected natural ligands during the MDS was confirmed through the calculation of the $\Delta \mathrm{G}_{\text {bind }}$, showing for the 3 ligands an average $\Delta \mathrm{G}_{\text {bind }}$ higher than the co-crystallized ligand.

The NPs identified at present, do not pretend to directly enter into clinical trials as potential $\mathrm{M}^{\text {pro }}$ inhibitors, however, through our results we can consider the main biomolecular interactions and structural information of the best ligands for further design and optimization of SARS-CoV-2 $\mathrm{M}^{\text {pro }}$ inhibitors.

\section{ACKNOWLEDGMENTS}

The team gives special thanks to Siembra EP (Imbabura, Ecuador) for the support with Quinde 1 supercomputer. To Dr. Meng Guo, Dr. Li Wang (National Supercomputing Center in Jinan, China) for their support with the implementation of Gromacs and Vina software and helpful discussions, to Dr. Ana Valderrama (Universidad Nacional de Ingeniería, Perú) for her personal financial contribution to the project, to Dr. Debanjan Sen (BCDA College of Pharmacy \& Technology, India) and Dr. Ricardo Silva (Alluriam Health and Wellness Inc., Florida, USA) for their valuable insights on an earlier version of the manuscript. Finally, remembering that \#SinCienciaNoHayFuturo.

\section{CONFLICT OF INTEREST}

The authors declare that they have no conflict of interest.

\section{FUNDING STATEMENT}

No funding was received from any academic or government entity for this research.

\section{ORCID ID}

Wilmar Puma-Zamora: https://orcid.org/0000-0001-9101-531X

Fabián Jiménez: https://orcid.org/0000-0003-1385-7946

Jesus Antonio Alvarado-Huayhuaz: https://orcid.org/0000-0003-4912-3178

Gerson Cordova-Serrano: https://orcid.org/0000-0002-5591-0322

Pierre-Marie Allard: https://orcid.org/0000-0003-3389-2191

Mariano Prado Acosta: https://orcid.org/0000-0003-4120-538X

Gustavo E. Olivos-Ramírez: https://orcid.org/0000-0002-9300-1779

Héctor Condori-Alagón: https://orcid.org/0000-0001-6720-2967

Ihosvany Camps: https://orcid.org/0000-0001-5898-1313

\section{DATA AVAILABILITY STATEMENT}

Data and materials are available upon request to the corresponding author.

\section{SUPPLEMENTARY MATERIAL}

Movies of molecular dynamics trajectories for all the complexes, made with VMD v1.9.3, can be found in:

https://tinyurl.com/yxe4xvwn 
Abraham, M. J., Murtola, T., Schulz, R., Páll, S., Smith, J. C., Hess, B., \& Lindah, E. (2015). Gromacs: High performance

437

438

439

440

441

442

443

444

445

446

447

448

449

450

451

452

453

454

455

456

457

458

459

460

461

462

463

464

465

466

467

468

469

470

471 molecular simulations through multi-level parallelism from laptops to supercomputers. SoftwareX, 1-2, 19-25. https://doi.org/10.1016/j.softx.2015.06.001

Allard, P. M., Péresse, T., Bisson, J., Gindro, K., Marcourt, L., Pham, V. C., Roussi, F., Litaudon, M., \& Wolfender, J. L. (2016). Integration of Molecular Networking and In-Silico MS/MS Fragmentation for Natural Products Dereplication. Analytical Chemistry, 88(6), 3317-3323. https://doi.org/10.1021/acs.analchem.5b04804

Arnold, C. (2020). Race for a vaccine. New Scientist, 245(3274), 44-47. https://doi.org/10.1016/S0262-4079(20)30600-X

Berendsen, H. J. C., Postma, J. P. M., van Gunsteren, W. F., DiNola, A., \& Haak, J. R. (1984). Molecular dynamics with coupling to an external bath. The Journal of Chemical Physics, 81(8), 3684-3690. https://doi.org/10.1063/1.448118

Berry, M., Fielding, B., \& Gamieldien, J. (2015). Potential Broad Spectrum Inhibitors of the Coronavirus 3CLpro: A Virtual Screening and Structure-Based Drug Design Study. Viruses, 7(12), 6642-6660. https://doi.org/10.3390/v7122963

Burley, S. K., Berman, H. M., Bhikadiya, C., Bi, C., Chen, L., Di Costanzo, L., Christie, C., Dalenberg, K., Duarte, J. M., Dutta, S., Feng, Z., Ghosh, S., Goodsell, D. S., Green, R. K., Guranović, V., Guzenko, D., Hudson, B. P., Kalro, T., Liang, Y., ... Zardecki, C. (2019). RCSB Protein Data Bank: biological macromolecular structures enabling research and education in fundamental biology, biomedicine, biotechnology and energy. Nucleic Acids Research, 47(D1), D464-D474. https://doi.org/10.1093/nar/gky1004

Bzówka, M., Mitusińska, K., Raczyńska, A., Samol, A., Tuszyński, J. A., \& Góra, A. (2020). Structural and evolutionary analysis indicate that the sars-COV-2 mpro is a challenging target for small-molecule inhibitor design. International Journal of Molecular Sciences, 21(9). https://doi.org/10.3390/ijms21093099

C, S., S, D. K., Ragunathan, V., Tiwari, P., A, S., \& P, B. D. (2020). Molecular docking, validation, dynamics simulations, and pharmacokinetic prediction of natural compounds against the SARS-CoV-2 main-protease. Journal of Biomolecular Structure \& Dynamics, 1-27. https://doi.org/10.1080/07391102.2020.1815584

Chen, N., Zhou, M., Dong, X., Qu, J., Gong, F., Han, Y., Qiu, Y., Wang, J., Liu, Y., Wei, Y., Xia, J., Yu, T., Zhang, X., \& Zhang, L. (2020). Epidemiological and clinical characteristics of 99 cases of 2019 novel coronavirus pneumonia in Wuhan, China: a descriptive study. The Lancet, 395(10223), 507-513. https://doi.org/10.1016/S0140-6736(20)302117

COVID-19 Map. (2020). COVID-19 Map - Johns Hopkins Coronavirus Resource Center. Johns Hopkins Coronavirus Resource Center. https://coronavirus.jhu.edu/data/mortality\%0Ahttps://coronavirus.jhu.edu/map.html

Darden, T., York, D., \& Pedersen, L. (1993). Particle mesh Ewald: An N · $\log (\mathrm{N})$ method for Ewald sums in large systems. The Journal of Chemical Physics, 98(12), 10089-10092. https://doi.org/10.1063/1.464397

DiMasi, J. A., Grabowski, H. G., \& Hansen, R. W. (2016). Innovation in the pharmaceutical industry: New estimates of R\&D costs. Journal of Health Economics, 47, 20-33. https://doi.org/10.1016/j.jhealeco.2016.01.012

Endstrasser, F., Braito, M., Linser, M., Spicher, A., Wagner, M., \& Brunner, A. (2020). The negative impact of the COVID19 lockdown on pain and physical function in patients with end-stage hip or knee osteoarthritis. Knee Surgery, Sports Traumatology, Arthroscopy, 28(8), 2435-2443. https://doi.org/10.1007/s00167-020-06104-3

Feinstein, W. P., \& Brylinski, M. (2015). Calculating an optimal box size for ligand docking and virtual screening against 
experimental and predicted binding pockets. Journal of Cheminformatics, 7(1), 18. https://doi.org/10.1186/s13321015-0067-5

Fischer, A., Sellner, M., Neranjan, S., Smieško, M., \& Lill, M. A. (2020). Potential inhibitors for novel coronavirus protease identified by virtual screening of 606 million compounds. International Journal of Molecular Sciences, 21(10), 3626. https://doi.org/10.3390/ijms21103626

Friesner, R. A., Banks, J. L., Murphy, R. B., Halgren, T. A., Klicic, J. J., Mainz, D. T., Repasky, M. P., Knoll, E. H., Shelley, M., Perry, J. K., Shaw, D. E., Francis, P., \& Shenkin, P. S. (2004). Glide: A New Approach for Rapid, Accurate Docking and Scoring. 1. Method and Assessment of Docking Accuracy. Journal of Medicinal Chemistry, 47(7), 1739-1749. https://doi.org/10.1021/jm0306430

Genheden, S., \& Ryde, U. (2015). The MM/PBSA and MM/GBSA methods to estimate ligand-binding affinities. Expert Opinion on Drug Discovery, 10(5), 449-461. https://doi.org/10.1517/17460441.2015.1032936

Gentile, D., Patamia, V., Scala, A., Sciortino, M. T., Piperno, A., \& Rescifina, A. (2020). Putative inhibitors of SARSCOV-2 main protease from a library of marine natural products: A virtual screening and molecular modeling study. Marine Drugs, 18(4), 225. https://doi.org/10.3390/md18040225

Glombitza, K. W., \& Schmidt, A. (1999). Nonhalogenated and halogenated phlorotannins from the brown alga Carpophyllum angustifolium. Journal of Natural Products, 62(9), 1238-1240. https://doi.org/10.1021/np990076c

Gu, J., Gui, Y., Chen, L., Yuan, G., Lu, H. Z., \& Xu, X. (2013). Use of Natural Products as Chemical Library for Drug Discovery and Network Pharmacology. PLoS ONE, 8(4), e62839. https://doi.org/10.1371/journal.pone.0062839

Guan, W., Ni, Z., Hu, Y., Liang, W., Ou, C., He, J., Liu, L., Shan, H., Lei, C., Hui, D. S. C., Du, B., Li, L., Zeng, G., Yuen, K. Y., Chen, R., Tang, C., Wang, T., Chen, P., Xiang, J., ... Zhong, N. (2020). Clinical characteristics of coronavirus disease 2019 in China. New England Journal of Medicine, 382(18), 1708-1720. https://doi.org/10.1056/NEJMoa2002032

Gurung, A. B., Ali, M. A., Lee, J., Abul Farah, M., \& Al-Anazi, K. M. (2020). In silico screening of FDA approved drugs reveals ergotamine and dihydroergotamine as potential coronavirus main protease enzyme inhibitors. Saudi Journal of Biological Sciences, 27(10), 2674-2682. https://doi.org/10.1016/j.sjbs.2020.06.005

Gyebi, G. A., Ogunro, O. B., Adegunloye, A. P., Ogunyemi, O. M., \& Afolabi, S. O. (2020). Potential inhibitors of coronavirus 3-chymotrypsin-like protease (3CLpro): an in silico screening of alkaloids and terpenoids from African medicinal plants. Journal of Biomolecular Structure and Dynamics, 1-13. https://doi.org/10.1080/07391102.2020.1764868

Halgren, T. A. (1996). Merck molecular force field. I. Basis, form, scope, parameterization, and performance of MMFF94. In Journal of Computational Chemistry (Vol. 17, Issues 5-6, pp. 490-519). https://doi.org/10.1002/(SICI)1096987X(199604)17:5/6<490::AID-JCC1>3.0.CO;2-P

He, X., Lau, E. H. Y., Wu, P., Deng, X., Wang, J., Hao, X., Lau, Y. C., Wong, J. Y., Guan, Y., Tan, X., Mo, X., Chen, Y., Liao, B., Chen, W., Hu, F., Zhang, Q., Zhong, M., Wu, Y., Zhao, L., ... Leung, G. M. (2020). Temporal dynamics in viral shedding and transmissibility of COVID-19. Nature Medicine, 26(5), 672-675. https://doi.org/10.1038/s41591020-0869-5

Heller, S. R., McNaught, A., Pletnev, I., Stein, S., \& Tchekhovskoi, D. (2015). InChI, the IUPAC International Chemical Identifier. Journal of Cheminformatics, 7(1), 23. https://doi.org/10.1186/s13321-015-0068-4

Hess, B., Bekker, H., Berendsen, H. J. C., \& Fraaije, J. G. E. M. (1997). LINCS: A Linear Constraint Solver for molecular 
511

512

513

514

515

516

517

518

519

520

521

522

523

524

525

526

527

528

529

530

531

532

533

534

535

536

537

538

539

540

541

542

543

544

545

546

547

548

549

simulations. Journal of Computational Chemistry, 18(12), 1463-1472. https://doi.org/10.1002/(SICI)1096987X(199709)18:12<1463::AID-JCC4>3.0.CO;2-H

Ibrahim, M. A. A., Abdeljawaad, K. A. A., Abdelrahman, A. H. M., \& Hegazy, M. E. F. (2020). Natural-like products as potential SARS-CoV-2 Mpro inhibitors: in-silico drug discovery. Journal of Biomolecular Structure and Dynamics, 1-13. https://doi.org/10.1080/07391102.2020.1790037

Jacobson, M. P., Pincus, D. L., Rapp, C. S., Day, T. J. F., Honig, B., Shaw, D. E., \& Friesner, R. A. (2004). A Hierarchical Approach to All-Atom Protein Loop Prediction. Proteins: Structure, Function and Genetics, 55(2), 351-367. https://doi.org/10.1002/prot.10613

Jiménez-Alberto, A., Ribas-Aparicio, R. M., Aparicio-Ozores, G., \& Castelán-Vega, J. A. (2020). Virtual screening of approved drugs as potential SARS-CoV-2 main protease inhibitors. Computational Biology and Chemistry, 88 , 107325. https://doi.org/10.1016/j.compbiolchem.2020.107325

Jin, Z., Du, X., Xu, Y., Deng, Y., Liu, M., Zhao, Y., Zhang, B., Li, X., Zhang, L., Peng, C., Duan, Y., Yu, J., Wang, L., Yang, K., Liu, F., Jiang, R., Yang, X., You, T., Liu, X., .. Yang, H. (2020). Structure of Mpro from SARS-CoV-2 and discovery of its inhibitors. Nature, 582(7811), 289-293. https://doi.org/10.1038/s41586-020-2223-y

Jorgensen, W. L., Chandrasekhar, J., Madura, J. D., Impey, R. W., \& Klein, M. L. (1983). Comparison of simple potential functions for simulating liquid water. The Journal of Chemical Physics, 79(2), 926-935. https://doi.org/10.1063/1.445869

Kandeel, M., \& Al-Nazawi, M. (2020). Virtual screening and repurposing of FDA approved drugs against COVID-19 main protease. Life Sciences, 251, 117627. https://doi.org/10.1016/j.lfs.2020.117627

Kanhed, A. M., Patel, D. V., Teli, D. M., Patel, N. R., Chhabria, M. T., \& Yadav, M. R. (2020). Identification of potential Mpro inhibitors for the treatment of COVID-19 by using systematic virtual screening approach. Molecular Diversity. https://doi.org/10.1007/s11030-020-10130-1

Karnon, J. (2020). A Simple Decision Analysis of a Mandatory Lockdown Response to the COVID-19 Pandemic. Applied Health Economics and Health Policy, 18(3), 329-331. https://doi.org/10.1007/s40258-020-00581-w

Keusgen, M., \& Glombitza, K. W. (1997). Pseudofuhalols from the brown alga Sargassum spinuligerum. Phytochemistry, 46(8), 1403-1415. https://doi.org/10.1016/S0031-9422(97)00510-4

Khalifa, S. A. M., Yosri, N., El-Mallah, M. F., Guo, R. G. Z., Musharraf, S. G., Du, M., Khatib, A., Xiao, J., Saeed, A., ElSeedi, H. H. R., Zhao, C., Efferth, T., \& El-Seedi, H. R. (2020). Screening for natural and derived bio-active compounds in preclinical and clinical studies: one of the frontlines of fighting the coronaviruses pandemic. Phytomedicine, 153311. https://doi.org/10.1016/j.phymed.2020.153311

Khuroo, M. S., Khuroo, M., Khuroo, M. S., Sofi, A. A., \& Khuroo, N. S. (2020). COVID-19 Vaccines: A Race Against Time in the Middle of Death and Devastation! Journal of Clinical and Experimental Hepatology. https://doi.org/10.1016/j.jceh.2020.06.003

Kinjo, J., Suyama, K., \& Nohara, T. (1995). Triterpenoidal saponins from Dumasia Truncata. Phytochemistry, 40(6), 17651767. https://doi.org/10.1016/0031-9422(95)00545-I

Laskowski, R. A., \& Swindells, M. B. (2011). LigPlot+: Multiple ligand-protein interaction diagrams for drug discovery. Journal of Chemical Information and Modeling, 51(10), 2778-2786. https://doi.org/10.1021/ci200227u

Li, J., Abel, R., Zhu, K., Cao, Y., Zhao, S., \& Friesner, R. A. (2011). The VSGB 2.0 model: A next generation energy model for high resolution protein structure modeling. Proteins: Structure, Function, and Bioinformatics, 79(10), 


\section{4-2812. https://doi.org/10.1002/prot.23106}

LigPrep. (2018). Schrödinger Release 2018-4, Schrödinger LLC, New York - NY.

Lin, X., Li, X., \& Lin, X. (2020). A Review on Applications of Computational Methods in Drug Screening and Design. Molecules, 25(6), 1375. https://doi.org/10.3390/molecules25061375

Lindert, S., Tallorin, L., Nguyen, Q. G., Burkart, M. D., \& McCammon, J. A. (2015). In silico screening for Plasmodium falciparum enoyl-ACP reductase inhibitors. Journal of Computer-Aided Molecular Design, 29(1), $79-87$. https://doi.org/10.1007/s10822-014-9806-3

Liu, L., Heinrich, M., Myers, S., \& Dworjanyn, S. A. (2012). Towards a better understanding of medicinal uses of the brown seaweed Sargassum in Traditional Chinese Medicine: A phytochemical and pharmacological review. Journal of Ethnopharmacology, 142(3), 591-619. https://doi.org/10.1016/j.jep.2012.05.046

Lu, R., Zhao, X., Li, J., Niu, P., Yang, B., Wu, H., Wang, W., Song, H., Huang, B., Zhu, N., Bi, Y., Ma, X., Zhan, F., Wang, L., Hu, T., Zhou, H., Hu, Z., Zhou, W., Zhao, L., ... Tan, W. (2020). Genomic characterisation and epidemiology of 2019 novel coronavirus: implications for virus origins and receptor binding. The Lancet, 395(10224), 565-574. https://doi.org/10.1016/S0140-6736(20)30251-8

Madhavi Sastry, G., Adzhigirey, M., Day, T., Annabhimoju, R., \& Sherman, W. (2013). Protein and ligand preparation: Parameters, protocols, and influence on virtual screening enrichments. Journal of Computer-Aided Molecular Design, 27(3), 221-234. https://doi.org/10.1007/s10822-013-9644-8

Majumder, R., \& Mandal, M. (2020). Screening of plant-based natural compounds as a potential COVID-19 main protease inhibitor: an in silico docking and molecular dynamics simulation approach. Journal of Biomolecular Structure \& Dynamics, 1-16. https://doi.org/10.1080/07391102.2020.1817787

Mazzini, S., Musso, L., Dallavalle, S., \& Artali, R. (2020). Putative SARS-CoV-2 Mpro Inhibitors from an In-House Library of Natural and Nature-Inspired Products: A Virtual Screening and Molecular Docking Study. Molecules, 25(16), 3745. https://doi.org/10.3390/molecules25163745

Mesecar, A. D. (2020). RCSB PDB - 6W63: Structure of COVID-19 main protease bound to potent broad-spectrum noncovalent inhibitor X77. In Rcsb. https://doi.org/10.2210/pdb6W63/pdb

Mirza, M. U., \& Froeyen, M. (2020). Structural elucidation of SARS-CoV-2 vital proteins: Computational methods reveal potential drug candidates against main protease, Nsp12 polymerase and Nsp13 helicase. Journal of Pharmaceutical Analysis, 10(4), 320-328. https://doi.org/10.1016/j.jpha.2020.04.008

Morris, G. M., Ruth, H., Lindstrom, W., Sanner, M. F., Belew, R. K., Goodsell, D. S., \& Olson, A. J. (2009). Software news and updates AutoDock4 and AutoDockTools4: Automated docking with selective receptor flexibility. Journal of Computational Chemistry, 30(16), 2785-2791. https://doi.org/10.1002/jcc.21256

Muramatsu, T., Takemoto, C., Kim, Y. T., Wang, H., Nishii, W., Terada, T., Shirouzu, M., \& Yokoyama, S. (2016). SARS$\mathrm{CoV}$ 3CL protease cleaves its C-terminal autoprocessing site by novel subsite cooperativity. Proceedings of the National Academy of Sciences of the United States of America, 113(46), 12997-13002. https://doi.org/10.1073/pnas.1601327113

Musa, M. A., Wahab, R. A., \& Huyop, F. (2018). Homology modelling and in silico substrate-binding analysis of a Rhizobium sp. RC1 haloalkanoic acid permease. Biotechnology and Biotechnological Equipment, 32(2), 339-349. https://doi.org/10.1080/13102818.2018.1432417

Nakladal, D., Buikema, H., Romero, A. R., Lambooy, S. P. H., Bouma, J., Krenning, G., Vogelaar, P., van der Graaf, A. C., 
589

590

591

592

593

594

595

596

597

598

599

600

601

602

603

604

605

606

607

608

609

610

611

612

613

614

615

616

617

618

619

620

621

622

623

624

625

626

627

Groves, M. R., Kyselovic, J., Henning, R. H., \& Deelman, L. E. (2019). The (R)-enantiomer of the 6-chromanol derivate SUL-121 improves renal graft perfusion via antagonism of the $\alpha 1$-adrenoceptor. Scientific Reports, 9(1), 13. https://doi.org/10.1038/s41598-018-36788-0

National Institutes of Health. (2020). NIH COVID-19 Treatment Guidelines. https://www.covid19treatmentguidelines.nih.gov/

Nonaka, G. ichiro, Nakayama, S., \& Ishioka, I. N. (1989). Tannins And Related Compounds. LXXXIII. Isolation And Structures of Hydrolyzable Tannins, Phillyraeoidins A-E From Quercus Phillyraeoides. Chemical and Pharmaceutical Bulletin, 37(8), 2030-2036. https://doi.org/10.1248/cpb.37.2030

O’Boyle, N. M., Banck, M., James, C. A., Morley, C., Vandermeersch, T., \& Hutchison, G. R. (2011). Open Babel: An Open chemical toolbox. Journal of Cheminformatics, 3(10), 33. https://doi.org/10.1186/1758-2946-3-33

Olsson, M. H. M., SØndergaard, C. R., Rostkowski, M., \& Jensen, J. H. (2011). PROPKA3: Consistent treatment of internal and surface residues in empirical p K a predictions. Journal of Chemical Theory and Computation, 7(2), 525-537. https://doi.org/10.1021/ct100578z

Oso, B. J., Adeoye, A. O., \& Olaoye, I. F. (2020). Pharmacoinformatics and hypothetical studies on allicin, curcumin, and gingerol as potential candidates against COVID-19-associated proteases. Journal of Biomolecular Structure and Dynamics, 16, 1-12. https://doi.org/10.1080/07391102.2020.1813630

Panda, P. K., Arul, M. N., Patel, P., Verma, S. K., Luo, W., Rubahn, H. G., Mishra, Y. K., Suar, M., \& Ahuja, R. (2020). Structure-based drug designing and immunoinformatics approach for SARS-CoV-2. Science Advances, 6(28), eabb8097. https://doi.org/10.1126/sciadv.abb8097

Parrinello, M., \& Rahman, A. (1980). Crystal Structure and Pair Potentials: A Molecular-Dynamics Study. Physical Review Letters, 45(14), 1196-1199. https://doi.org/10.1103/PhysRevLett.45.1196

Paules, C. I., Marston, H. D., \& Fauci, A. S. (2020). Coronavirus Infections-More Than Just the Common Cold. JAMA, 323(8), 707. https://doi.org/10.1001/jama.2020.0757

Qinfen, Z., Jinming, C., Xiaojun, H., Huanying, Z., Jicheng, H., Ling, F., Kunpeng, L., \& Jingqiang, Z. (2004). The life cycle of SARS coronavirus in Vero E6 cells. Journal of Medical Virology, 73(3), 332-337.

https://doi.org/10.1002/jmv.20095

Rao, P., Shukla, A., Parmar, P., Rawal, R. M., Patel, B. V., Saraf, M., \& Goswami, D. (2020). Proposing a fungal metabolite-flaviolin as a potential inhibitor of 3CLpro of novel coronavirus SARS-CoV-2 identified using docking and molecular dynamics. Journal of Biomolecular Structure and Dynamics, 1-13. https://doi.org/10.1080/07391102.2020.1813202

Ratia, K., Pegan, S., Takayama, J., Sleeman, K., Coughlin, M., Baliji, S., Chaudhuri, R., Fu, W., Prabhakar, B. S., Johnson, M. E., Baker, S. C., Ghosh, A. K., \& Mesecar, A. D. (2008). A noncovalent class of papain-like protease/deubiquitinase inhibitors blocks SARS virus replication. Proceedings of the National Academy of Sciences of the United States of America, 105(42), 16119-16124. https://doi.org/10.1073/pnas.0805240105

Rostkowski, M., Olsson, M. H., Søndergaard, C. R., \& Jensen, J. H. (2011). Graphical analysis of pH-dependent properties of proteins predicted using PROPKA. BMC Structural Biology, 11(1), 6. https://doi.org/10.1186/1472-6807-11-6

Sayed, A. M., Alhadrami, H. A., El-Gendy, A. O., Shamikh, Y. I., Belbahri, L., Hassan, H. M., Abdelmohsen, U. R., \& Rateb, M. E. (2020). Microbial natural products as potential inhibitors of SARS-CoV-2 main protease (Mpro). Microorganisms, 8(7), 1-17. https://doi.org/10.3390/microorganisms8070970 
628

629

630

631

632

633

634

635

636

637

638

639

640

641

642

643

644

645

646

647

648

649

650

651

652

653

654

655

656

657

658

659

660

661

662

663

664

665

666

Seifert, E. (2014). OriginPro 9.1: Scientific data analysis and graphing software - Software review. Journal of Chemical Information and Modeling, 54(5), 1552. https://doi.org/10.1021/ci500161d

Sen, D., Debnath, P., Debnath, B., Bhaumik, S., \& Debnath, S. (2020). Identification of potential inhibitors of SARS-CoV-2 main protease and spike receptor from 10 important spices through structure-based virtual screening and molecular dynamic study. Journal of Biomolecular Structure and Dynamics, 1-22. https://doi.org/10.1080/07391102.2020.1819883

Sharma, M., \& Surani, S. (2020). Searching an Effective Therapy for the Coronavirus Pandemic: Do We See Light at the End of the Tunnel? Cureus, 12(3), e7415. https://doi.org/10.7759/cureus.7415

Sherman, W., Day, T., Jacobson, M. P., Friesner, R. A., \& Farid, R. (2006). Novel procedure for modeling ligand/receptor induced fit effects. Journal of Medicinal Chemistry, 49(2), 534-553. https://doi.org/10.1021/jm050540c

Sigalapalli, D. K., Rangaswamy, R., \& Tangellamudi, N. D. (2020). Novel huperzine A based NMDA antagonists: Insights from molecular docking, ADME/T and molecular dynamics simulation studies. RSC Advances, 10(43), 25446-25455. https://doi.org/10.1039/d0ra00722f

Tahir ul Qamar, M., Alqahtani, S. M., Alamri, M. A., \& Chen, L. L. (2020). Structural basis of SARS-CoV-2 3CLpro and anti-COVID-19 drug discovery from medicinal plants. Journal of Pharmaceutical Analysis, 10(4), 313-319. https://doi.org/10.1016/j.jpha.2020.03.009

Thakur, K., Kumar, N., \& Sharma, N. R. (2020). Effect of the Pandemic and Lockdown on Mental Health of Children. Indian Journal of Pediatrics, 87(7), 552. https://doi.org/10.1007/s12098-020-03308-w

Trott, O., \& Olson, A. J. (2009). AutoDock Vina: Improving the speed and accuracy of docking with a new scoring function, efficient optimization, and multithreading. Journal of Computational Chemistry, 31(2), NA-NA. https://doi.org/10.1002/jcc.21334

Tsuji, M. (2020). Potential anti-SARS-CoV-2 drug candidates identified through virtual screening of the ChEMBL database for compounds that target the main coronavirus protease. FEBS Open Bio, 10(6), 995-1004. https://doi.org/10.1002/2211-5463.12875

Wang, F., Yang, W., \& Hu, X. (2019). Discovery of high affinity receptors for dityrosine through inverse virtual screening and docking and molecular dynamics. International Journal of Molecular Sciences, 20(1). https://doi.org/10.3390/ijms20010115

Wang, R., Lu, Y., \& Wang, S. (2003). Comparative evaluation of 11 scoring functions for molecular docking. Journal of Medicinal Chemistry, 46(12), 2287-2303. https://doi.org/10.1021/jm0203783

WHO Director-General's Conference. (2020). WHO Director-General's opening remarks at the media briefing on COVID19 - 11 March 2020. https://www.who.int/dg/speeches/detail/who-director-general-s-opening-remarks-at-the-mediabriefing-on-covid-19---11-march-2020

World Health Organization. (2020a, July 7). Rational use of personal protective equipment for coronavirus disease 2019( COVID-19). World Health Organization. https://apps. who.int/iris/bitstream/handle/10665/331695/WHO-2019-nCovIPC_PPE_use-2020.3-eng.pdf

World Health Organization. (2020b, July 8). Naming the coronavirus disease (COVID-19) and the virus that causes it. World Health Organization. https://www.who.int/emergencies/diseases/novel-coronavirus-2019/technicalguidance/naming-the-coronavirus-disease-(covid-2019)-and-the-virus-that-causes-it

Wu, C., Liu, Y., Yang, Y., Zhang, P., Zhong, W., Wang, Y., Wang, Q., Xu, Y., Li, M., Li, X., Zheng, M., Chen, L., \& Li, 
667

668

669

670

671

672

673

674

675

676

677

678

679

680

681

H. (2020). Analysis of therapeutic targets for SARS-CoV-2 and discovery of potential drugs by computational methods. Acta Pharmaceutica Sinica B, 10(5), 766-788. https://doi.org/10.1016/j.apsb.2020.02.008

Wu, F., Zhao, S., Yu, B., Chen, Y. M., Wang, W., Song, Z. G., Hu, Y., Tao, Z. W., Tian, J. H., Pei, Y. Y., Yuan, M. L., Zhang, Y. L., Dai, F. H., Liu, Y., Wang, Q. M., Zheng, J. J., Xu, L., Holmes, E. C., \& Zhang, Y. Z. (2020). A new coronavirus associated with human respiratory disease in China. Nature, 579(7798), 265-269. https://doi.org/10.1038/s41586-020-2008-3

Yang, H., Xie, W., Xue, X., Yang, K., Ma, J., Liang, W., Zhao, Q., Zhou, Z., Pei, D., Ziebuhr, J., Hilgenfeld, R., Kwok, Y. Y., Wong, L., Gao, G., Chen, S., Chen, Z., Ma, D., Bartlam, M., \& Rao, Z. (2005). Design of wide-spectrum inhibitors targeting coronavirus main proteases. PLoS Biology, 3(10), e324. https://doi.org/10.1371/journal.pbio.0030324

Yu, J., Zhou, Y., Tanaka, I., \& Yao, M. (2009). Roll: A new algorithm for the detection of protein pockets and cavities with a rolling probe sphere. Bioinformatics, 26(1), 46-52. https://doi.org/10.1093/bioinformatics/btp599

Zhang, L., Lin, D., Sun, X., Curth, U., Drosten, C., Sauerhering, L., Becker, S., Rox, K., \& Hilgenfeld, R. (2020). Crystal structure of SARS-CoV-2 main protease provides a basis for design of improved a-ketoamide inhibitors. Science, 368(6489), 409-412. https://doi.org/10.1126/science.abb3405 